12th LUMEN International Scientific Conference Rethinking Social Action. Core Values in Practice | RSACVP 2019 | 15-17 May 2019 | lasi - Romania

\title{
Comparative Study on the Effectiveness of the Means of Strengthening the Technical Element - Shooting with the Laces Finalization
}

\author{
Adrian PRICOP \\ https://doi.org/10.18662/lumproc. 174
}

How to cite: Pricop, A. (2019). Comparative Study on the Effectiveness of the Means of Strengthening the Technical Element Shooting with the Laces Finalization. In C. Ignatescu (ed.), 12th LUMEN International Scientific Conference Rethinking Social Action. Core Values in Practice, 15-17 May 2019, Iasi - Romania (pp. 274-285). Iasi, Romania: LUMEN Proceedings. https://doi.org/10.18662/lumproc.174 


\title{
Comparative Study on the Effectiveness of the Means of Strengthening the Technical Element - Shooting with the Laces Finalization
}

\author{
Adrian PRICOP 1
}

\begin{abstract}
This study seeks to improve the process of strengthening the technical elements aimed at completing the attack actions by shooting with the lace's finalization. The aim of the paper is to promote a complex of methods and means to strengthen the shooting techniques. We have conducted our study was on a 24 students sample practicing football in the representative team of the University Politehnica of Bucharest.

The athletes were organized in two groups: the experimental group (12 subjects) and the control group 12 (subjects). The age of those taking part in the study ranges from 19 to 23 years old. The research took place between October 17 and March 23, 2018, during which we used, in training the subjects, a set of methods and means to strengthen the technical element, the shoot to the gate finalization.

In the training process, the experimental group specifically practiced, 20 minutes in each lesson, programs based on strengthening the shoot to the gate finalization while the control group followed the classical training program.

The main research methods we utilized are these: the scientific documentation, the experiment, the observation, the graphic method and the statistical mathematical interpretation.

Following the research conducted and by processing the results obtained, we observed outstanding progress in final test compared to initial test.

The comparison of the results obtained in the final evaluation shows statistically significant differences between the two groups. Using the complex of methods and means contributes to making efficient the process of instruction and education.
\end{abstract}

Keywords: football; shooting ; students ; technical elements;

\footnotetext{
1 Lecturer, Ph. D, University Politehnica of Bucharest, Bucharest, Romania, cretu_trans@yahoo.com 


\section{Introduction}

In recent years, football at university level has become a sports game that has gathered an impressive number of practitioners around it, becoming increasingly present both in physical education lessons as a means of growth and improvement of motricity together with will intellectual qualities, as well as in university sports competitions. The competitiveness, the spectacularity, the multitude of the actions and the technical and tactical combinations of attack and defense, which succeeded at a rapid pace, lead the constant change and improvement of the training methodology. Thus, the importance of enriching the concept of training through the modernization of methods and means of training in order to increase the students' performance in competitions becomes obvious.

Due to the practical experience we had during the trainings with the UPB (University Politehnica of Bucharest) representative football team, we remarked the need to better the level of technical training in accordance with the contemporary requirements of football.

The evolutionary feature, due to the new developments in the technical performances in football, determined the choice of the present research topic aimed at the innovative valorization of the scientific information and the practical experience assimilated during the activity carried out with UPB (University Politehnica of Bucharest) representative football team.

The main objective of the technical training in football in nonspecialist higher education is the consolidation, learning of new procedures and the improvement of the technical skills needed to deal with the attack and the defense.

The field specialists consider the technique of football as the ensemble of the specific means of football through which the players perform on the one hand the actions with the ball (its control and movement), and on the other hand, the maneuvers (with and without the ball) necessary for the effective as well as rational action and cooperation so as to achieve the goal pursued [3].

The content of the technical training program consists of the following technical techniques in the attack: hitting the ball with the outer, inner and full lace, on the spot and on the way to the partner and towards the goal; hitting the ball with the head and from jumping; taking over the ball with the leg and on the chest; dodges (passes, shooting); shooting in force to the goal.

In the present paper we paid special attention to the technical process - hitting the ball with the full lace because we consider it a technical 
element that is very important in the football, which intervenes in changing the direction of the game, in launching a counterattack and especially in finalizing some actions, respectively the execution of the shootings to the goal.

The technical elements aiming at finalization in football is a topic often addressed by the researchers in the field [1], [5], [6], [7]. All the studies address performance or high performance and refer to junior, senior, female and male football [4], [8], [9], [10]. This paper aims to address an intermediate sample of subjects who are superior to those who practice football in the physical education lesson or as leisure activities but who do not reach the level of performance teams.

The determination of the training programs, adapted to the specific age of the students, their level of physical and technical training must be a constant concern of the specialists in the field, whose purpose is to increase the efficiency of the players in the official competitions materialized by winning. Achieving superior performance in football needs several factors and relies, to large extent, on utilizing modern training methods [2].

\section{Material and methods}

\subsection{Research Aim}

The purpose of the approach is to develop a complex of new methodologies as well as means, by pointing out the optimal structures of operation in order to strengthen the technical elements focused on the full lace shooting finalization in football.

The purpose of the study consists in the experimental validation of the means effectiveness in order to strengthen the technical elements aiming at finalizing in football of the students who are part of the University Politehnica of Bucharest (U.P.B.) representative team.

\subsection{Research Hypothesis}

The aim of the approach is to develop a complex of innovative means, but also methods, by finding the optimal structures for operating in order to strengthen the technical elements focused on the full lace shooting finalization in football.

The purpose of the study consists in the experimental validation of the means effectiveness in order to strengthen the technical elements aiming 
at finalizing in football of the students who are part of the University Politehnica of Bucharest (U.P.B.) representative team.

\subsection{Research Methods}

The principal methodologies of scientific research employed are as follows:

- the direct observation method in the training lessons with the students and the indirect observation method by studying the planning documents;

- the experimental method, in which the constatative and ameliorative type experiment was used;

- the evaluation method used in the determination of the methodological structures aimed at strengthening the technical elements for finalization in football, materialized in the following evaluation trials:

- trial 1, leading the ball over $20 \mathrm{~m}$ and full lace shooting finalization from $25 \mathrm{~m}$;

- trial2, leading the ball between the stakes on a distance of 20 $\mathrm{m}$ full lace shooting finalization from $25 \mathrm{~m}$;

- trial3, passes in two on a distance of $20 \mathrm{~m}$ and full lace shooting finalization by shooting to the goal from $25 \mathrm{~m}$.

The evaluation in trial 1 deals with the quantification of the successes in 45 ", the evaluation in trial 2 tackles the goals scored after completing 6 successful attempts, and trial3 quantifies the number of successes for 60 ".

In the trials, the ball mustn't touch the stakes and the finalization to the goal needs to be done in a manner in which the ball should not touch the playing surface.

- the statistical-mathematical method, which facilitated the evolution analysis of the results obtained by the subjects investigated. The statistical and mathematical indicators used in the research were as follows: the arithmetic mean, the coefficient of variability, the standard deviation as well as the independent student T-test to verify if the arithmetic means of the two samples (the experimental and control group) differ significantly;

- the graphical method, which allowed the intuitive and synthetic presentation of research data. 


\subsection{Subjects, place and strategy of the research}

The research took place in the U.P.B sports hall for a 24 students sample, aged 19 and 23, members of the representative football team. The subjects were split in two groups: the experimental group (12 subjects) and the control group 12 (subjects).

The experimental research was conducted over a period of 6 months and followed these steps:

- from October 2 to October 6 2018, the initial testing of the two subjects' groups took place;

- from October 6, 2017 to March 23, 2018, we applied, in the experimental group preparation, the training program elaborated;

- between 26 and 30 March 2018, the final testing of the two groups investigated took place.

In the experiment we intervened in the students' trainings from the experimental group, so as to improve the trainings process by applying means, concretized in a succession of operational structures, which aim especially at consolidating and improving the technical element of finalization in football. The operational structures elaborated showed a higher level of difficulty in accordance with the principles of sports training. All these means were rationalized and standardized in special training programs and staggered throughout the training period. The experimenting of the exercise structures was made taking into account the students' level of training at that time as well as the interest shown by the subjects.

The experimental group carried out a two-week training program, in which 20 minutes were allocated to the operational structures proposed to be experienced, and the control group worked after the usual program with the same number of weekly trainings.

The students willingly took part in this test but we also had the informed written consent of every student participating, in accordance with the ethical and medical conditions. The subjects who participated in the experiment were clinically healthy and agreed to the way this was performed. The subjects were randomly selected for the study.

\subsection{Results}

In this research, we computed the following statistics parameters: the arithmetic mean $\left(,{ }^{-} \mathrm{X}\right.$ "), standard deviation $(" \sigma ")$, coefficient of variability $\left(\mathrm{Cv}_{-} \mathrm{O} \%\right)$, "Student" test calculated " $\mathrm{t}$ " to determine the authenticity between the groups and the progress significance, in our case $\mathrm{N}=11$, the critical 
value of $t$ is $t \geq 2.201$ at the value of $p<0.05$. The data presentation was shown both in tables and in graphs. Tables 1 and 2 point out the comparative results obtained by the experimental and control group at the initial and final tests. Figures 1, 2, 3, 4, 5, 6 represent graphically the experimental evolution of the two groups in the initial and final tests.

Table 1. Comparative analysis for the results of the experimental and control group in the initial test.

\begin{tabular}{|c|c|c|c|c|c|c|c|}
\hline \multirow{3}{*}{ TESTS } & \multicolumn{7}{|c|}{ STATISTICAL AND MATHEMATICAL INDICATORS } \\
\hline & \multicolumn{2}{|c|}{$\overline{\boldsymbol{x}} / \pm \sigma$} & \multirow{2}{*}{$\begin{array}{c}\begin{array}{c}\text { Mean } \\
\text { def }\end{array} \\
G 1-G 2\end{array}$} & \multicolumn{2}{|c|}{$\mathrm{Cv}$} & \multirow{2}{*}{$\begin{array}{c}\text { t Test dep. } \\
t\end{array}$} & \multirow[b]{2}{*}{$\mathrm{p}$} \\
\hline & G1 & G2 & & G1 & G2 & & \\
\hline Test 1. & 3,63 p. $/ \pm 0,67$ & 3,52 p. $/ \pm 0,51$ & $0,05 \mathrm{p}$. & $\begin{array}{c}18,4 \\
5\end{array}$ & $\begin{array}{l}14,3 \\
8\end{array}$ & 0,21 & $>0,05$ \\
\hline Test 2. & 2.91 g. $/ \pm 0.66$ & 2.58 g. $/ \pm 0,66$ & 0,33 & $\begin{array}{c}22,6 \\
8\end{array}$ & $\begin{array}{c}25,5 \\
8\end{array}$ & 1,22 & $>0,05$ \\
\hline Test 3 . & 3.16 g. $/ \pm 0.57$ & 2.75 g. $/ \pm 0.62$ & 0,41 & $\begin{array}{c}18,0 \\
3\end{array}$ & $\begin{array}{c}22,5 \\
4\end{array}$ & 1,7 & $>0,05$ \\
\hline
\end{tabular}

Table 2. Comparison analysis of the results in the experimental and control group at the final test.

\begin{tabular}{|c|c|c|c|c|c|c|c|}
\hline \multirow{3}{*}{ TESTS } & \multicolumn{7}{|c|}{ STATISTICAL AND MATHEMATICAL INDICATORS } \\
\hline & \multicolumn{2}{|c|}{$\overline{\bar{X}} / \pm \sigma$} & \multirow{2}{*}{$\begin{array}{c}\begin{array}{c}\text { Mean } \\
\text { def }\end{array} \\
G 1-G 2\end{array}$} & \multicolumn{2}{|c|}{$\mathrm{Cv}$} & \multirow{2}{*}{$\begin{array}{l}\text { t Test dep. } \\
t\end{array}$} & \multirow[b]{2}{*}{$\mathrm{p}$} \\
\hline & G1 & G2 & & G1 & G2 & & \\
\hline Test 1. & $4.91 \mathrm{p} . / \pm 0.79$ & 3.66 p. $/ \pm 0.49$ & $1,25 \mathrm{p}$ & $\begin{array}{c}16,0 \\
8\end{array}$ & $\begin{array}{l}13,3 \\
8\end{array}$ & 4,63 & $<0,05$ \\
\hline Test 2. & 4 g. $/ \pm 0,95$ & 2,88 g. $/ \pm 0,57$ & 1,12 & $\begin{array}{c}23,7 \\
5\end{array}$ & $\begin{array}{c}19,7 \\
9\end{array}$ & 3,62 & $<0,05$ \\
\hline Test 3. & 4,66 g. $/ \pm 1,23$ & 2,91 g. $/ \pm 0,66$ & 1,75 & $\begin{array}{c}26,3 \\
6\end{array}$ & $\begin{array}{c}22,6 \\
8\end{array}$ & 4,32 & $<0,05$ \\
\hline
\end{tabular}

In trial 1 (Table 1), leading the ball over a distance of $20 \mathrm{~m}$ and full lace finalization from $25 \mathrm{~m}$ distance, at the initial test, we notice that the arithmetic mean in the initial test is of 3.63 points for the EG, and the CG gained a score of 3.52. The difference in the arithmetic means is of 0.05 points. The standard deviation in the initial EG test is of 0.67 and for the CG it is of 0.51 . The coefficient of variability is of $18,45 \%$ for the EG and of $14,38 \%$ for the CG, hence the dispersion is found to be average, and the 
sample is relatively uniform. The value for $\mathrm{t}$ between the EG and CG is of 0.21 , hence $\mathrm{p}<0.05$, therefore the differences are statistically insignificant between the two tests.

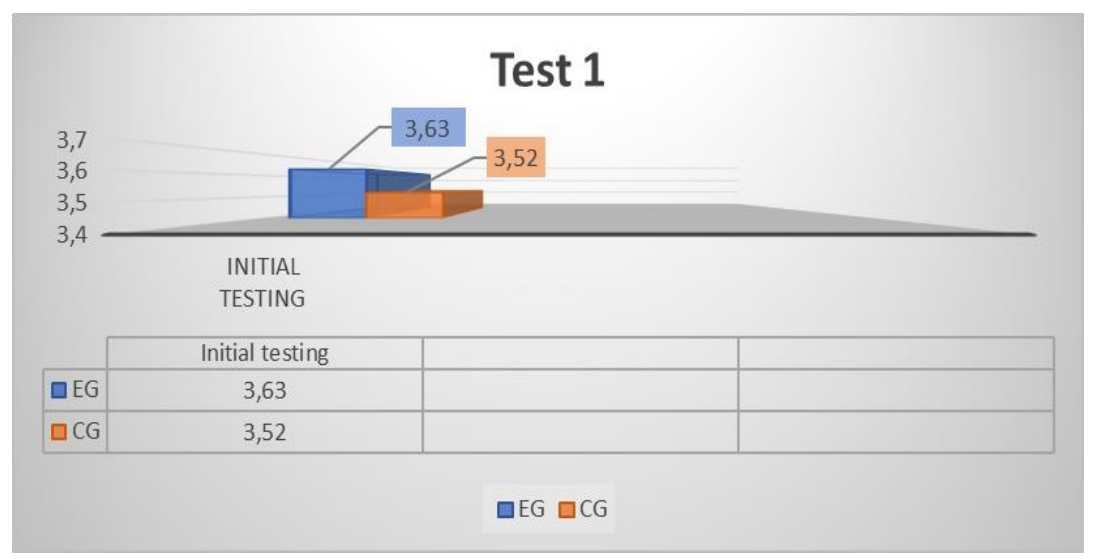

Figure 1. Results of comparison for the EG and CG obtained at the initial test - trial 1 leading the ball over a distance of $20 \mathrm{~m}$ and full lace shooting finalization from $25 \mathrm{~m}$.

In trial 2 (Table 1), leading the ball between the stakes on a distance of $20 \mathrm{~m}$ and full lace shooting finalization from $25 \mathrm{~m}$, the arithmetic mean of the EG in the initial test is of 2.91 points and of the CG of 2.58 points. The difference in the arithmetic means between the EG and CG2 is of 0.33 goals. The coefficient of variability "Cv" is of $22.68 \%$ at the initial test for the EG, and of $25.58 \%$ for the CG, hence the sample is non-homogenous. The value for the "Student" test computed " $t$ " is of 1.22 hence, $p<0.05$, the differences being statistically insignificant for the means in the two groups. 


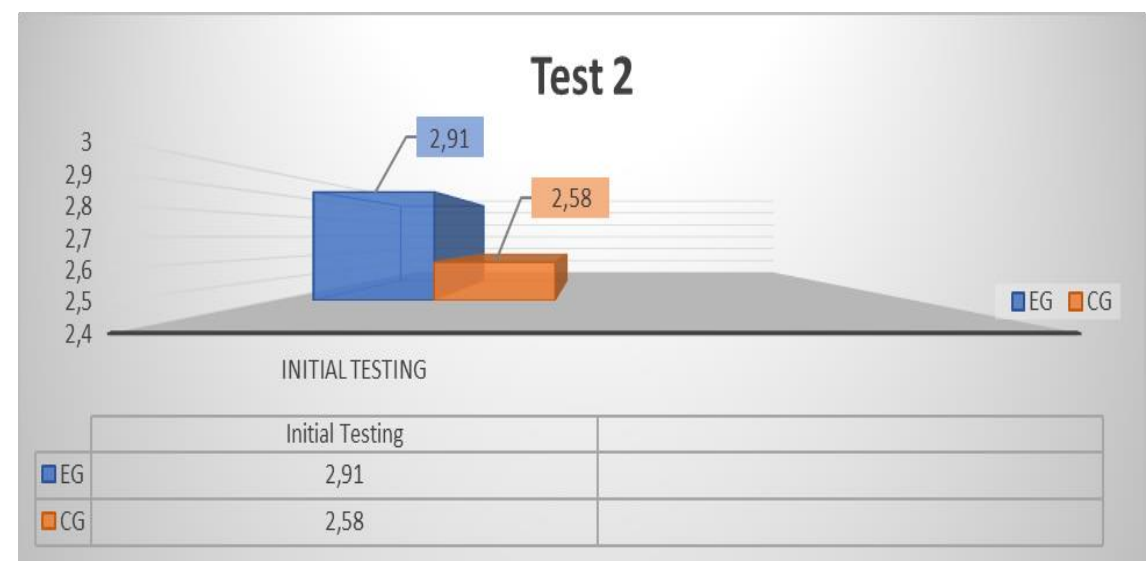

Figure 2. Comparing results in the EG and CG at the initial test-trial 2, leading the ball between the stakes over a $20 \mathrm{~m}$ distance and full lace shooting finalization from $25 \mathrm{~m}$.

In what regards trial 3 (Table 1), passes in two on the distance of 20 $\mathrm{m}$ and full lace shooting finalization to the goal from $25 \mathrm{~m}$, the arithmetic mean in the initial EG test is of 3.16 points, and for the CG of 2.75 points. The difference in the arithmetic means concerning the EG-CG is of 0.41. The standard deviation has values in the initial test for the EG of 0.55, and for the CG of 0.62 . The coefficient of variability "Cv" bears the percentage of $18.03 \%$ for EG at the initial test and of $22.54 \%$ in the CG, the sample being non-uniform. The value of the " $t$ " "Student" test for the EG-CG is of 1.7 , hence $\mathrm{p}<0.05$, therefore the differences are statistically insignificant between the means of the two tests.

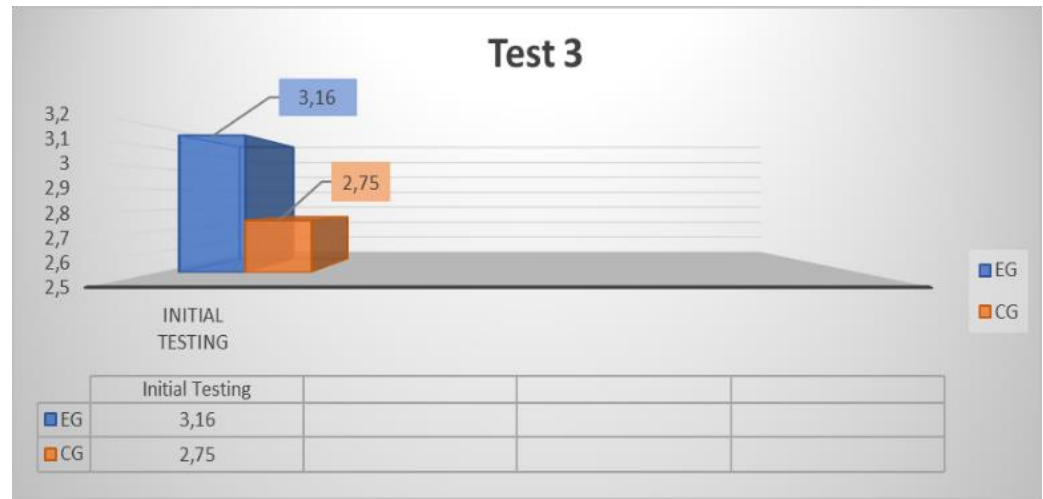

Figure 3. Comparative results of the EG and CG obtained at the initial test-trial 3 -passes in two on $20 \mathrm{~m}$ distance and full lace shooting finalization to the goal from $25 \mathrm{~m}$. 
At the end of the experiment, the results obtained in trial 1 (Table 2), leading the ball on a distance of $20 \mathrm{~m}$ and full lace shooting finalization from $25 \mathrm{~m}$ distance indicate a value of the EG arithmetic mean of 4.91 points, and for the CG of 3.66 points, the arithmetic mean difference between the EGCG being of 1.25 points. The spread degree of the string values represented by the standard deviation has the values at the initial test of 0.79 for the EG and of 0.49 for the CG. The coefficient of variability "Cv" has the percentage of $14.08 \%$ in the final EG test and of $13.38 \%$ for the CG final test, so the sample is relatively homogeneous. The value in the "Student" test we calculated as " $t$ " in the EG-CG is of 4.63 , hence $p<0.05$, therefore we have increased statistic differences on the means in the two groups.

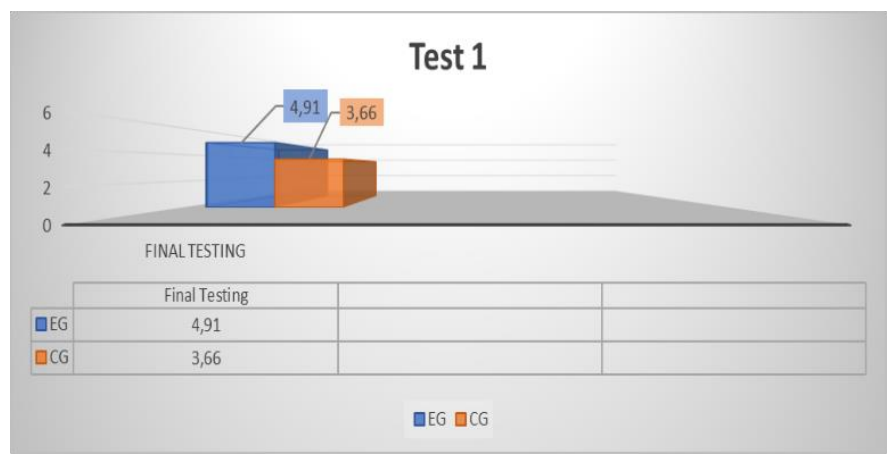

Figure 4. Results for comparison of the EG and CG in the final test-trial 1 leading the ball over a distance of $20 \mathrm{~m}$ and full lace shooting finalization from $25 \mathrm{~m}$.

In trial 2 (Table 2), leading the ball on a $20 \mathrm{~m}$ distance and full lace shooting finalization from $25 \mathrm{~m}$, the arithmetic mean for the final test is of 4 points for the EG and of 2.88 points for the CG. The difference in the arithmetic means between the EG-CG is of 1.12 points. The coefficient of variability "Cv" displays the value of $0.95 \%$ in the initial EG test, and of $0.57 \%$ in the CG initial test, therefore our sample is homogeneous. The value of the "Student" calculated " $t$ " between the EG-CG is of 3.62, hence $p$ $<0.05$, so we find important statistic differences regarding the means for the two groups. 


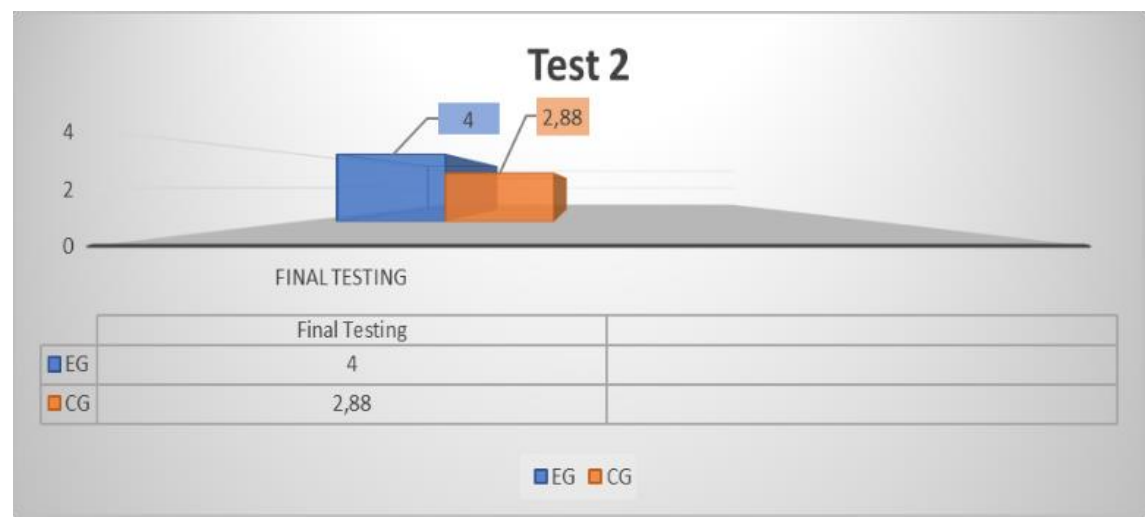

Figure 5. Comparative results of the EG and CG in the final test - trial 2, leading the ball through the stakes on a distance of $20 \mathrm{~m}$ and full lace shooting finalization from $25 \mathrm{~m}$.

In trial 3 (Table 2), passes in two on $20 \mathrm{~m}$ and full lace shooting finalization to the goal from $25 \mathrm{~m}$, at the final test, the arithmetic mean value is of 4.66 points for the EG, and for the CG of 2.91 points. The difference in the arithmetic means between the EG-CG is of 1.75 points. The standard deviation is of 1.23 for the EG and of 0.66 for the CG. The coefficient of variability "Cv" is of $26.36 \%$ for the EG testing and of $22.68 \%$ for CG testing. The value of the "Student" test calculated " $\mathrm{t}$ " between the EG1-CG is of 4.32 (hence $\mathrm{p}<0.05$ ); the statistic differences are of signification between the two groups means.

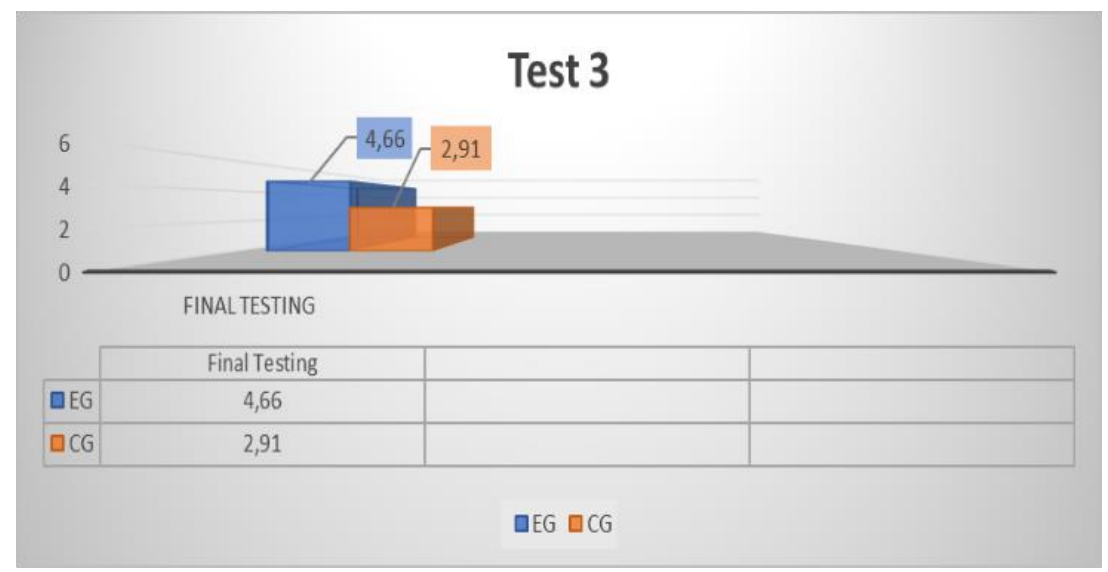

Figure 6. Results of comparison regarding the EG and CG in the final test - trial 3 -passes in two on $20 \mathrm{~m}$ distance and full lace shooting finalization to the goal from $25 \mathrm{~m}$. 


\section{Conclusions}

The superior results obtained in the final phase of the research by the experimental group compared to the control group attest that the training programs used have positively influenced the level of the technical element investigated. The operational structures, converted into training programs and applied to the experimental group, were the ones that made the difference in the preparation of the two groups investigated, which means that the means that were used in the training are efficient.

The judicious elaboration of the operational means focused on the consolidation and improvement of the technical element aimed at finalizing in football and their inclusion in training programs adapted to the age specifics and the level of training of the students investigated are operations that led to the improvement of sports performances, which validates the first research hypothesis.

The standardization and algorithmizing of the operational structures, as well as their judicious planning in the training programs, led to the efficiency of the methodological content meant for the consolidation of the technical element - full lace shooting finalization, which confirms the second hypothesis of the research.

By the experimental validation of the didactic strategy used, we can state that the data recorded can complete the sources existing in the specialty literature, and the programs elaborated can be included in the training of the football teams both at university level and at the performance level.

\section{References}

[1] Bradley PS., et al. High-intensity activity profiles of elite soccer players at different performance levels. J Strength Cond Res. 2010;24(9): 2343-2351.

[2] Ciolcă SM. Capacitatea de performanță în fotbal. Bucureşti: Editura Cartea Universitară; 2005. p. 60

[3] Ciolcă SM. Tehnica şi tactica jocului de fotbal. Curs de bază. Editura Fundației România de Mâine; 2006. p. 20

[4] Krustrup P, et al., Physical demands during an elite female soccer game: importance of training status. Medicine and Science in Sports and Exercise. 2005;37(7):1242-1248.

[5] Lago C. The influence of match location, quality of opposition, and match status on possession strategies in professional association football. Journal of Sports Sciences. 2009;27(13):1463-1469.

[6] Lago C, Martin R. Determinants of possession of the ball in soccer. Journal of Sports Sciences. 2007;25(9):969-974. 
[7] Lago-Ballesteros J, Lago-Penas C. Performance in team sports: Identifying the keys to success in soccer. Journal of Human Kinetics. 2010;25:85-91.

[8] Mara JK, Wheeler KW, Lyons K. Attacking strategies that lead to goal scoring opportunities in high level women's football. International Journal of Sports Science \& Coaching. 2012;7(3):2012.

[9] Rampinini E, et al., Technical performance during soccer matches of the Italian Serie A league: effect of fatigue and competitive level. Journal of Science and Medicine in Sport. 2009;12(1):227-233.

[10] Rees G., et al., The effect of match status on attacking strategies in the English Championship. In M Hughes, et al., editors. Research Methods and Performance Analysis, University of West Hungary; 2011. p. 172-177. 